\title{
EXPERIENCIA DE DESARROLLO DE LA SEDE DE LIMÓN, UNIVERSIDAD DE COSTA RICA 2002-2010: LOGROS Y DESAFÍOS
}

\section{DEVELOPMENT EXPERIENCE OF LIMON CAMPUS 2002-2010, UNIVERSITY OF COSTA RICA: ACHIEVEMENTS AND CHALLENGES}

\author{
Ivonne Lepe Jorquera ${ }^{1}$
}

\begin{tabular}{|l|l}
\hline Recibido: 03.03.20 & Aprobado: 05.06.20 \\
\hline
\end{tabular}

DOI: $10.15517 /$ isucr.v21i44.43926

\section{Resumen}

Este artículo presenta una descripción de la experiencia de desarrollo de la Sede de Limón, hoy Sede del Caribe, en el período 2002-2010. Constituye la sistematización de una experiencia de la regionalización de la educación superior en Costa Rica con un enfoque cuantitativo. Se revisaron documentos de la actividad pre, post y durante el período indicado. Los resultados muestran en cifras la transformación dada en el período de estudio. Se concluye que, a pesar del salto cualitativo y cuantitativo ocurrido en la unidad académica en esa etapa, los desafíos se mantienen y los avances resultan insuficientes para alcanzar las necesidades que crecen día con día en la región.

Palabras clave: Limón; Costa Rica; educación superior; descentralización educativa; región de prioridad educativa - Sede Caribe.

\begin{abstract}
This article presents a description of the development experience of the Limón Campus, now the Caribbean Campus, in the period 2002-2010. It constitutes the systematization of an experience of regionalization of higher education in Costa Rica with a quantitative approach. Documents from the pre-, post-, and during the indicated period were reviewed. The results show in figures the transformation given in the study period. As a conclusion the author found that regardless of the qualitative and quantitative leap in this academic unit at the stage, challenges remain. Furthermore, all the progress mentioned has been insufficient to meet the needs that are growing every day in the region.

Key words: Limón; Costa Rica; higher education; decentralized education; priority education region - Caribbean Campus.

\footnotetext{
$\overline{1}$ Costarricense/chilena. Profesora Asociada, Universidad de Costa Rica. Docente-Investigadora en la Sede del Caribe, Universidad de Costa Rica, Limón, Costa Rica. Magister en Administración de Empresas con énfasis en Mercadeo y Finanzas; Magister en Ingeniería Civil, Especialidad Hidráulica. Email: ilepe2000@gmail.com.
} 


\section{Introducción}

La Universidad pública juega un rol preponderante en la sociedad costarricense en temas sociales, económicos, culturales, políticos, tecnológicos, científicos y medioambientales, tanto en el centro como en la periferia del país. El proceso de regionalización en Costa Rica, a partir de la creación en 1968 del primer recinto regional en San Ramón, (Castro Sánchez, 2011) ha logrado aumentar la cobertura de sus programas, el presupuesto y la cantidad de estudiantes que atiende; con todo, la transformación en las sedes regionales universitarias sigue siendo insuficiente en comparación con las sedes centrales (Arias, 2018).

Este artículo responde a la necesidad de visibilizar el proceso de desarrollo de la regionalización de la educación superior, específicamente, la experiencia de la Sede de Limón ${ }^{2}$ de la Universidad de Costa Rica (UCR), ubicada en Limón, Costa Rica, en el período 2002-2010. Importante destacar que en la investigación previa realizada, no se encontró una sistematización similar a la planteada en este escrito. El objetivo fundamental de la investigación realizada fue recoger la experiencia del período indicado, partiendo de una revisión bibliográfica y describir el desarrollo de esta sede universitaria desde el punto de vista cuantitativo y realizar un análisis cualitativo de la situación del período. Asimismo resaltar la importancia de la presencia de la educación superior en las regiones.

Primeramente, se abordará el tema de la regionalización mediante la revisión de posiciones de algunos autores de Latinoamérica; luego, se menciona la génesis del tema de la regionalización en Costa Rica; posteriormente, se hace un breve recorrido por los antecedentes, el entorno y el contexto de la hoy Sede del Caribe. Los resultados se presentan estructurados en tres partes: desarrollo académico, desarrollo estudiantil y gestión administrativa.

\section{Consideraciones teóricas}

Abordar el tema de la regionalización implica revisar, en primer lugar, el concepto región. Según, O’Brien (1999) región implica que haya periferia y un núcleo centralizador dominante, o sea un Estado-nación con fraccionamientos secundarios. Lo contrario sería una sociedad de

\footnotetext{
${ }^{2}$ La llamada Sede de Limón desde su creación ha tenido diferentes nombres y estatus, según la etapa en que se encontraba. Se creó en 1975, denominándose Servicio Descentralizado de Limón dependiente del Centro Regional del Atlántico (Turrialba). El 21 de abril de 1979, el Consejo Universitario decretó la creación del Centro Regional de Limón, ratificado el 19 de abril de 1980. El 17 de septiembre de 1987, por un acuerdo de la Asamblea Colegiada Representativa, los Centros Regionales pasaron a llamarse sedes. En el 2010 pasó a llamarse Sede del Caribe.
} 
segmentos de cooperación, libre y sin dominación de ninguno de estos. Abarca (2010) señala que en estudios históricos, el punto de vista nacional ha primado sobre el regional. Con relación a lo anterior, este autor plantea la potencialidad de incurrir en tres situaciones riesgosas: Construir la identidad nacional con base en lo acaecido en la región central; desechar un enfoque sistémico, al ignorar lo periférico o considerándolo separado de lo nacional y/o establecer un enfoque reduccionista mediante la definición de los procesos regionales desvinculados de los nacionales o transfronterizos.

Este enfoque histórico podría extrapolarse a otros ámbitos, como en el caso de la educación, en el cual esta forma de visualizar lo regional ha traído como consecuencias: a) el establecimiento de programas de educación básica y media nacionales únicos sin considerar las diferencias regionales, b) en Limón, la multietnicidad que le caracteriza se ha tratado como algo que le compete solo al limonense y c) considerar que lo que sucede en Limón solo le concierne a esta provincia.

Según Rama (2015) en América Latina los procesos de regionalización surgen como resultado de luchas y de políticas, es decir, no responden a convergencia de criterios. Los limitados presupuestos de las regiones y la centralización de los ingresos estatales, así como de la toma de decisiones han evitado su fortalecimiento acorde con las necesidades existentes en cada una de ellas. Esto influye directamente en el desarrollo económico de las regiones al conferirles menor capital humano, con menos destrezas cognitivas que, a su vez, provoca deficiencia en los niveles de productividad y menos oportunidades de trabajo y de inversión (Montecinos, 2013). La desigualdad educativa constituye una de las expresiones de la desigualdad regional, la cual presenta diferencias entre la educación ofrecida y la demandada entre las diversas áreas geográficas en cuanto a calidad, cantidad, diversidad y pertinencia (Rama, 2015).

El caso de Costa Rica no ha sido una excepción. El conocimiento como base de movilidad social es cada vez más determinante; empero, el acceso disímil a una educación de calidad representa, ayer y hoy, un vector de desigualdad social porque el aprovechamiento de las mejores oportunidades estaría reservado para las personas provenientes de condiciones sociales más favorables (García Muñoz, 1998).

El Consejo Nacional de Educación Superior de Colombia (CESU) (Consejo Nacional de Educación Superior (CESU), 2014) plantea que la regionalización propicia que las personas sin importar el lugar geográfico o su origen sociocultural puedan acceder a la educación superior, lo cual implica favorecer la aptitud productiva de las regiones, para apoyar su desarrollo. Para ello se 
requiere una educación inclusiva, articulada, pertinente, equitativa y diversa en la región mediante la definición de su situación real, la identificar necesidades y las áreas de desarrollo requeridas para, de ese modo, planificar y poner en marcha los programas educativos pertinentes con los recursos necesarios a fin de elevar la calidad de vida de su población.

El impulso de las universidades regionales o sedes se ha desarrollado de manera muy distinta en los diferentes países o regiones. "En tal sentido, la construcción de estos sistemas está asociada a conflictos y tensiones alrededor de las formas de la descentralización, desconcentración o de los modelos mixtos o híbridos" (Martínez, 2002, citado por Rama, 2015, p. 306). La regionalización está asociada con la descentralización, la cual involucra una transformación político-administrativa, cuyo fin es llevar el poder de decisión y administración de sus recursos a las regiones y terminar con el centralismo y las características que se le confieren (Mattos, 1990). En ese sentido, Montecinos (2013) señala una posición concordante: "el centralismo tiene que ver con la falta de reconocimiento de las regiones y provincias como "sujetos políticos", y con la escasa transferencia y distribución de poder político administrativo y fiscal (descentralización) a organismos subnacionales" (Montecinos, 2013, p. 4). Desde su dimensión política e histórica la regionalización ha constituido un paradigma por el cual el Estado-nación se ha organizado sobre un enfoque de centralización educativa.

Costa Rica es un país pequeño pero diverso, con características socioeconómicas y culturales diferenciadas en las periferias. A partir de 1966, el II Congreso Universitario de la UCR decide llevar la educación superior a las regiones. Consecuentemente, la UCR crea, en 1968, el Centro Regional de San Ramón, iniciándose así la regionalización de la educación superior estatal pública. Paulatinamente, surgen los otros $\operatorname{Centros}^{3}$ Universitarios Regionales $^{4}$ de la UCR. Sin embargo, en el Tercer Congreso Universitario (1973-1974) se legitima la propuesta de regionalización de la institución, con la rectoría a cargo de Carlos Monge Alfaro, uno de sus impulsores más fuertes en este sentido(Castro Sánchez, 2011). Estas entidades regionales se concibieron con el objetivo de democratizar la enseñanza superior y fortalecer el desarrollo

\footnotetext{
${ }^{3}$ Los Centros regionales, por acuerdo de la Asamblea Colegiada Representativa del 17 de setiembre de 1987, pasaron a denominarse Sedes, (UCR, 2010a).

${ }^{4}$ Atlántico en Turrialba (1971); Guanacaste en Liberia (1972); Limón en 1975, como Servicio Descentralizado de Turrialba, en 1979 como Centro; Pacífico en Puntarenas, en 1975 como Servicio Descentralizado de la Sede de Occidente, en 1993 como Sede) y en 2007 se crea la Sede Interuniversitaria de Alajuela, la cual está conformada por las cuatro universidades públicas existentes hasta entonces (Universidad de Costa Rica (UCR), Universidad Nacional de Costa Rica (UNA), (Instituto Tecnológico de Costa Rica (TEC) y Universidad Estatal a distancia (UNED).
} 
intelectual en Costa Rica mediante un modelo de regionalización propio, sustentado en una estructura universitaria sólida y en la institucionalidad costarricense. No obstante, esta intención no evitó que el modelo fuera centralista desde el punto de vista administrativo, con propuestas a corto y mediano plazo para solventar los requerimientos locales y las demandas de las comunidades, propiciando, en especial en las tres primeras décadas, evidentes contrastes entre las sedes en diversos ámbitos del quehacer universitario. (Baltodano, 2015). Empero, es imprescindible recalcar que la regionalización conceptualizada en el III Congreso Universitario produjo una posición de avanzada con positiva y visionaria intención social integradora, parte de la cual se declara en los artículos 108 y 108bis del Estatuto Orgánico de la Universidad de Costa Rica (UCR, 1974). Es por ello que, a pesar de las dificultades y limitaciones del complejo proceso de regionalización de la educación superior estatal generado en Costa Rica a medio siglo de iniciado, es menester subrayar que las oportunidades se han brindado a miles de personas en el país, lo que ha propiciado una movilidad social en las regiones y un aporte al desarrollo de estas mediante los tres ejes sustantivos: docencia, acción social e investigación. Este proceso, ha sufrido una evolución importante, pero todavía queda mucho por analizar y ser replanteado a la luz de la globalización, del desarrollo tecnológico, los grandes cambios sociales, económicos, culturales y ambientales que sufre el país.

En la revisión de años posteriores a la etapa de estudio, el VI Informe del Estado de la Educación (CONARE, 2017), señala que el porcentaje de jóvenes entre 18 y 24 años que asistieron a la educación superior en la región central fue de 29.0\%; 30.6\% y 34\% en 2005, 2010 y 2016, respectivamente, mientras que en la región Huetar Caribe $e^{5}$ en el mismo período fue de 9.1\%; $13.3 \%$ y $14.9 \%$. En 2014, con 10,2\%, esta región tenía la menor representación en educación superior del país, mientras en la GAM la cifra alcanzaba el 34\% (CONARE, 2015). Aunque los programas de becas y beneficios de las universidades estatales han favorecido a los quintiles de menos ingresos; las cifras demuestran que la brecha persiste en el ámbito geográfico, especialmente entre la región central y otras regiones; por ejemplo, en cuanto a la cantidad y diversidad de carreras que se ofrecen (CONARE, 2017). El 69\% de los jóvenes de 18-24 años de la región Huetar Caribe que asisten a las universidades son los primeros de su familia en acceder a la educación superior,

\footnotetext{
${ }^{5}$ El Ministerio de Planificación de Costa Rica divide el país en 6 regiones de planificación: Región Central; Huetar Caribe; Chorotega; Huetar Norte; Pacífico Central y Brunca (Ministerio de Planificación de Costa Rica (MIDEPLAN), 2020). La región Huetar Caribe comprende toda la provincia de Limón.
} 
el promedio nacional es 57,5\% (CONARE, 2019). Un estudio del Observatorio Laboral de Profesiones (OLAP) revela que el 78,2\% de los graduados universitarios 2011-2013 de la región Huetar Caribe fueron de primera generación ${ }^{6}$, mayor al promedio nacional de 65,2\% (CONARE, 2019). El 67,4\% de este tipo de graduados de las universidades públicas obtuvo financiamiento mediante beca de la institución (CONARE, 2019).

En cuanto a la situación económico-social, el Instituto de Estadísticas y Censo (INEC), en la encuesta nacional a hogares, julio 2019, revela un ingreso promedio por hogar en la región Huetar Caribe inferior en 46,8\% a la región central y, el menor del país (Instituto Nacional de Estadísticas y Censo (INEC), 2019). Al mismo tiempo se presenta un incremento del desempleo en ese año, mayor al 12\% (Cordero, 2019).

\section{Antecedentes de la Sede de Limón y su entorno}

El denominado inicialmente Servicio Descentralizado de Limón se inició en 1975. Este ofrecía cursos de servicio y de Estudios Generales. En 1980, continúa la oferta de cursos de transferencia; no se ofrecían programas de carreras completas, pero sí programas de capacitación en las áreas de educación (primaria, preescolar y música) (UCR, 2010a). También la formación de peritos agrícolas, peritos deportivos y peritos portuarios. Entre 1980 y 1992 se ofrecieron programas de pregrado a nivel de profesorado en las áreas de Educación, así como el Diplomado en Informática Empresarial (impartido en todas las sedes regionales), Diplomado en Construcción ${ }^{7}$ y Bachillerato en Trabajo Social (UCR, 2010a). En 1993 se ofrece la licenciatura en Administración Portuaria, única opción existente en la UCR y en el país. En 1994 se desconcentra la carrera de Bachillerato en Enfermería. En 1998, el Bachillerato en Turismo Ecológico y se da la apertura del Bachillerato en Informática Empresarial, Bachillerato en Educación Preescolar, Licenciatura en Enfermería con énfasis en Salud de la Mujer y Perinatología y, en 1999, la Licenciatura en Educación Primaria. Entre 1999 y 2002 no hubo apertura de nuevas carreras (UCR, 2010a). Los profesorados creados debido al Plan de Emergencia ${ }^{8}$ tuvieron gran demanda; si bien,

\footnotetext{
${ }^{6}$ Primera generación: Se refiere a que ninguno de sus progenitores ni sus antepasados asistieron a educación superior.

7 "El 5 de junio de 1987 se firma el Convenio UCR-JAPDEVA con un aporte de $\$ 4$ millones anuales, para financiar las carreras de Diplomado en Informática, Diplomado en Construcción, capacitación de monitores deportivos y técnicos en peritos agrícolas" (UCR, 1995).

${ }^{8}$ Un déficit de docentes detectado a finales de la década de 1980 produjo una emergencia. Para subsanarla, en 1986 las universidades estatales (UCR, UNA, UNED) firmaron un convenio con el MEP (conocido como el Plan de Emergencia), conducente a la formación de educadores de primero y segundo ciclos en dos años. Para estos graduados se bajaron los estándares, no se exigió el examen de admisión ni la aprobación de un núcleo básico de materias y se
} 
otras carreras que requerían la aprobación de la Prueba de Aptitud Académica (PAA) tenían dificultades para llenar los cupos.

La creación de la Sede, producto de la demanda de la comunidad, así como su desarrollo ha atravesado un camino tortuoso. En 1967, año que coincide con la celebración del centenario de la apertura de Limón como puerto internacional (Soto-Quirós, 2012), se suministran las primeras manifestaciones documentadas de solicitudes de educación superior en la provincia (UCR, 2010a) mediante una demanda de la comunidad conformada por diversos sectores que se organizaron con ese fin. En 1977 se conforma un comité, el cual logra la donación de 7 hectáreas de terreno de parte de la comunidad. Después de deambular por diferentes instalaciones prestadas por instituciones, gracias a la donación del Ministerio de Obras Públicas y Transporte (MOPT), en 1978 comienza la construcción de los dos primeros pabellones de aulas (UCR, 1995).

Grandes esfuerzos y dificultades históricas han acompañado la gestión de esta unidad académica, como la situación económica de la zona con significativos índices de pobreza ${ }^{9}$, y la proliferación de universidades privadas ${ }^{10}$ a partir de 1986, cuya oferta comprendía carreras de corta duración y sin requisitos de ingreso, varias de las cuales se ubicaban en Limón con una oferta variada, entre ellas la Universidad Latinoamericana de Ciencia y Tecnología (ULACIT) y la Universidad Latina (UCR, 2010a). Asimismo, la apertura del mercado de la estiba en los muelles limonenses, cuya vigencia se dio el 25 de agosto de 1995 (Anónimo, 1996a), que provocó la disminución de los salarios de sus trabajadores (Anónimo, 1996b) ${ }^{11}$ constituye un factor que caracterizó la situación inestable de la Sede de Limón y de la provincia en general. Este último escenario probablemente generó en los jóvenes el interés por estudiar; a su vez, en forma paulatina propició su acercamiento a la educación superior.

\section{Contexto del período de estudio}

El período de estudio abarcó desde 2002 al 2010. En 2002, el reto era trascendental, ya que existía el inminente peligro de que la Sede fuera cerrada debido al decrecimiento de la matrícula,

\footnotetext{
levantaron requisitos para el otorgamiento del título académico. El único requisito de ingreso fue el bachillerato en educación media o la conclusión de estudios de la enseñanza diversificada. (CONARE, 2008).

${ }^{9}$ En 2002, el porcentaje de pobreza alcanzaba un 23.6\% en la región Huetar Atlántica (hoy denominada región Huetar Caribe), mientras que en la Región Central era de un 15.8\% (Programa Estado de la Nación (PEN), 2005).

${ }^{10}$ Pasando de 6 en 1986 a casi 50 en el 2000 a nivel nacional. Entre 1985 y el 2000 se crearon 47 universidades privadas (Ruiz, 2001).

${ }^{11}$ Hasta recién en el año 2004 se planteó el proyecto de ley (Arguedas, 2004); creación de un fideicomiso para el pago de una indemnización y finiquito a los trabajadores de la estiba de los muelles Limón y Moín, tramitado bajo el expediente legislativo $\mathrm{N}^{\circ} 15.580$ publicado en La Gaceta $\mathrm{N}^{\circ} 135$ del 12 de julio del 2004.
} 
tal como lo muestra la figura 4 (UCR, 2010a). Además, el presupuesto, los recursos humanos, el equipo tecnológico, el equipo de transporte, los materiales y la infraestructura eran insuficientes y, en algunos casos, inexistentes. Las autoridades de ese período en la Rectoría, el Dr. Gabriel Macaya Trejos, (1996-2004) y la Dra. Yamileth González García, (2004-2012) ofrecieron un decidido apoyo a la Sede de Limón. No obstante, las buenas intenciones y el impulso de las autoridades no habían sido suficientes por el rezago económico y social de la región y, por ende, el de la Sede también lo era. Esta no estaba cumpliendo con el rol que le correspondía y no estaba preparada para asumirlo con la eficiencia necesaria. La labor que se había desarrollado hasta entonces, con gran esfuerzo y apoyada por la comunidad, estudiantes, y funcionarios de la Sede, a la cabeza de los directores que les correspondió dirigirla en los períodos 1975 a 2001, consiguió levantarla con logros progresivos. Sin embargo, debido a las circunstancias de su génesis y sustento, la dotación de todos los tipos de recursos ${ }^{12}$ era escaso para operar correctamente. Las acciones universitarias en esos períodos no lograban cumplir a cabalidad con las expectativas y necesidades de desarrollo de todas las regiones.

Por otra parte, las escuelas ${ }^{13}$ no estaban convencidas de la necesidad de desconcentrar sus carreras hacia las regiones, en especial hacia Limón, debido a lo cual, pese a los esfuerzos no se lograba fortalecer la oferta académica. Es necesario señalar que lo vivido en Limón no es el único ejemplo en el país, aunque tal vez fue uno de los más drásticos, tampoco es exclusivo de Costa Rica.

En ese contexto, los retos para lograr una regionalización más acorde con las necesidades de la región de Limón planteaban el dilema de cómo llevar a cabo un proceso un tanto diferente al realizado hasta 2001. Incrementar la matrícula y aumentar la cantidad de carreras requirió incidir en el estudiantado colegial de la provincia para que lograran superar la Prueba de Aptitud Académica (PAA), examen de admisión necesario para ingresar a la UCR. La deserción estudiantil y la débil preparación (Programa Estado de la Nación (PEN), 2005, p. 276) han sido razones para que un porcentaje importante de los jóvenes no logren concluir la enseñanza secundaria. "Las

\footnotetext{
${ }^{12}$ Se clasifican en seis clases: humanos, financieros, materiales, mobiliario y equipo, planta física y tiempo (UCR, 2019a).

${ }^{13}$ La UCR está constituida por diferentes tipos de unidades académicas, 35 centros de investigación; 9 facultades; 47 escuelas; 3 estaciones experimentales; 13 institutos de investigación; 3 laboratorios de investigación; 5 sedes regionales, 7 recintos de sedes regionales, una finca interdisciplinaria, un observatorio oficial (UCR, 2020b) y (UCR, 2020c) un observatorio piloto (UCR, 2020d)
} 
estadísticas del MEP sobre cohortes completas muestran que de cada 1.000 niños que en 1990 entraron a primer grado, solo 270 llegaron a undécimo año y se prevé que de cada 1.000 que ingresaron al sistema en el 2000, se graduarán 349” (Programa Estado de la Nación (PEN), 2005, pág. 276). Según esta misma fuente, los estudiantes atribuyen la deserción a la ineficacia e ineficiencia del sistema y a las diferencias urbano/rural y educación pública/educación privada, entre otros factores.

El I Estado de la Educación (2005) presenta importantes diferencias regionales en los porcentajes promedio de aprobación general de bachillerato de 2004. Por tanto, la Dirección General de Limón reflejó uno de los tres peores resultados, un 50.3\%, mientras que Aguirre tenía un $80.5 \%$, aunque hay que destacar que Guápiles representaba una excepción en la provincia limonense, ya que con un $71.3 \%$ estaba entre los tres primeros mejores resultados de aprobación. Por otra parte, todas las direcciones regionales, excepto la de Guápiles ${ }^{14}$ presentaban una deserción mayor al 14.3\% (CONARE, 2005a).

Sin embargo, aquellos que concluyen la educación secundaria y aprueban bachillerato, no siempre tienen éxito en superar la barrera de ingreso a la educación superior (CONARE, 2019). Por ejemplo, en el período 2010-2011, de 2663 estudiantes inscritos para realizar la prueba de aptitud académica procedentes de Limón, el 77\% aplicó y solamente el $42 \%$ de los que aplicaron resultaron elegibles (UCR, 2020e) (Véase figura 1).

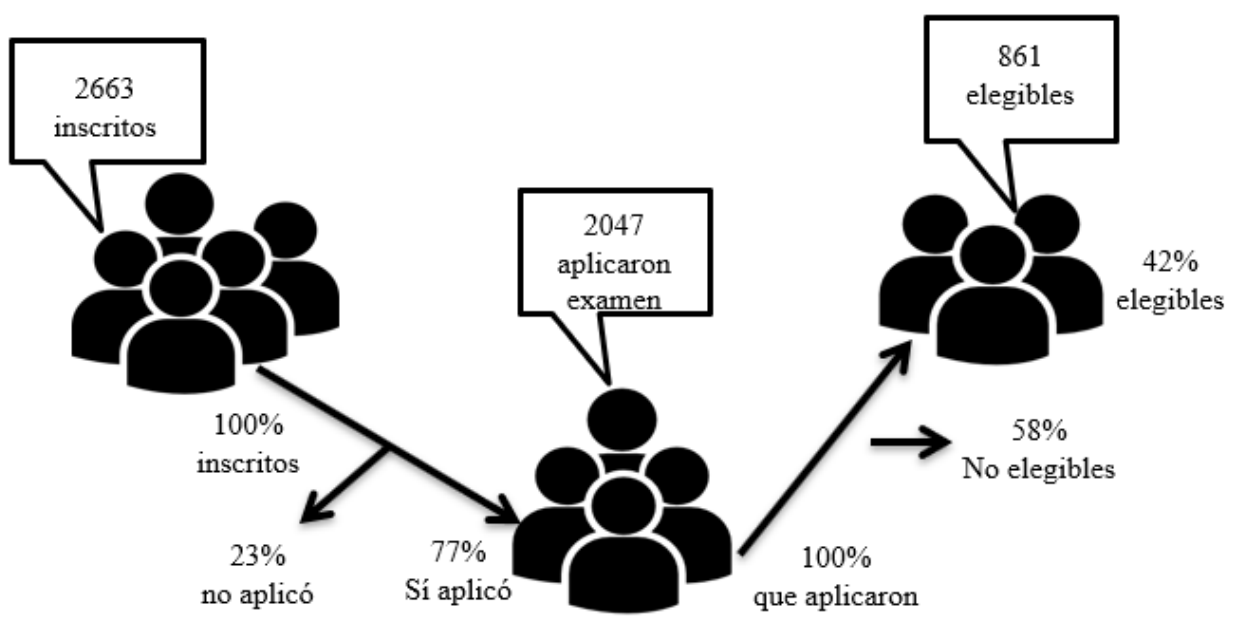

Figura 1. Estadística de admisión población estudiantil por etapas del proceso, procedentes de la provincia de Limón, período 2010-2011.

(Fuente: Elaboración propia con base en Sistema de Información Universitaria (SIUCR), Oficina de Registro e Información UCR, febrero 2020)

\footnotetext{
${ }^{14}$ En 2004, Guápiles presentaba una deserción intraanual en la educación secundaria de entre 11.8 y $14.3 \%$.
} 
El comportamiento anterior era parecido en los años anteriores. Por esta razón, las prioridades de la Sede fueron enrumbadas, en primer lugar, a consolidar el recurso humano que participara activamente del proceso de crecimiento y desarrollo de la Sede, así como modernizar los procedimientos haciendo uso intensivo de la tecnología. En 2002, la disponibilidad de personal administrativo y docente era mínimo, la mayoría de estos últimos eran profesionales con jornadas de tiempo parcial, así como nombramientos interinos discontinuos; existía poca credibilidad en la Sede tanto de parte de la comunidad como de la misma institución. Las primeras acciones de esa etapa comprendieron: planificación, proyectos de investigación y acción social tendientes a conocer la situación y a apoyar las necesidades de nivelación en colegios, así como propuestas concretas y su difusión; solicitudes de desconcentración de carreras y establecimiento de alianzas estratégicas con otras unidades académicas y con otras universidades; integración del Consejo de Sede y el personal docente y administrativo en las tareas planteadas.

Un rol importante jugó el Consejo de Áreas de Sedes Regionales (CASR), cuyos directores emprendieron una lucha tenaz en pro de la consecución de un aumento de los recursos para la regionalización. Algunos de los muchos esfuerzos realizados en ese entonces se plasman parcialmente en algunos documentos: Aspectos fundamentales de las actividades de las Sedes Regionales Período 1993-2003 (UCR, 2003) y Proceso de Admisión e Ingreso a Carrera en la UCR. Propuesta de las Sedes Regionales (UCR, 2004).

Como parte de la inserción activa en el proceso de alianzas interuniversitarias necesarias que ya se venían intentando articular, el 26 y 27 de septiembre de 2002 la Sede de Limón organizó y se constituyó en la anfitriona del "V Congreso de Regionalización Interuniversitaria 2002”, cuyo objetivo fue operacionalizar la regionalización de la educación superior estatal del país y, como tarea fundamental, fijar el rumbo hacia el cual debían dirigirse unidas de manera solidaria las sedes regionales de la educación superior estatal. En este evento participaron representantes de las cuatro universidades públicas, con la presencia de sus rectores.

Posteriormente, las políticas del Consejo Nacional de Rectores, CONARE, plasmadas en el Plan de Educación Superior Universitaria Estatal 2006-2010 incluyeron el Eje de Desarrollo Regional, con objetivos estratégicos, los cuales cito textualmente: “a) Impulsar la regionalización interuniversitaria de forma que contemple las necesidades por región, b) Fortalecer la capacidad académica de las Sedes Regionales y c) Articular esfuerzos entre las instituciones universitarias 
para dar un mejor servicio a las zonas rurales" (CONARE, 2005b, pág. 41). Es necesario indicar que, en este proceso de colaboración, las acciones de trabajo interuniversitario no estuvieron exentas de dificultades. En ese entonces, la UCR contaba ${ }^{15}$ con cinco sedes regionales: Sede de Occidente, Sede del Atlántico, Sede de Guanacaste, Sede del Pacífico y Sede de Limón.

Se acota que un director de Sede Regional de la UCR tiene la responsabilidad de: administrar un campus, o más de uno en algunos casos (considerando las sedes que tienen recintos), velar por todas las actividades que la Universidad realiza, coordinar docencia con varias carreras; acción social con varios proyectos de Trabajo Comunal (TCU), Extensión Docente y Extensión Cultural; investigación con proyectos y actividades, vida estudiantil con sus departamentos (becas, orientación, trabajo social, salud odontológica, médica, registro, residencias, entre otros) y Administración con Servicios Generales (oficiales de seguridad, departamento de suministro, recursos humanos, oficina de administración financiera (OAF), departamento de apoyo informático, compras, manejo de audiovisuales, bodega, personal de limpieza, choferes, encargados de laboratorio, mantenimiento de instalaciones (deportivas, aulas, laboratorios, biblioteca, residencias, etc.) Todas estas funciones las realiza con presupuesto limitado. Aunado a ello, le corresponde representar a la Sede ante organismos locales y nacionales, atender las demandas de la comunidad y de la región en general. En Limón, por ejemplo, se encuentran: el Consejo Regional de Desarrollo de Limón (COREDES PROLI) ${ }^{16}$ y el Consejo Directivo del Colegio Universitario de Limón (CUNLIMÓN).

\section{Metodología}

Este artículo se generó a partir de la sistematización de una experiencia académicoadministrativa, la cual tiene un enfoque cuantitativo. El diseño de la investigación parte de la propia práctica, mediante la descripción de la experiencia adquirida por la autora en la Sede de Limón, la cual se basa en datos recopilados a través del período 2002-2010 y que fueron incluidos en informes o documentos elaborados como memorias, informes de labores de la Dirección, de la Vicerrectoría de Vida Estudiantil, del Consejo de Área de Sedes Regionales (CASR), Rectoría, registros de la

\footnotetext{
${ }^{15}$ Actualmente también forma parte de la Sede Interuniversitaria de Alajuela y la Sede de Golfito recientemente creada. ${ }^{16}$ El Consejo Regional de Desarrollo de Limón (COREDES PROLI) se creó por Decreto Ejecutivo N $^{\circ} 33778$ MIDEPLAN-CI del 18 de mayo de 2007, con la finalidad de colaborar en el desarrollo de la provincia de Limón, mediante la participación de los representantes institucionales y comunales de la región. Su objetivo era lograr una mejor coordinación y articulación interinstitucional.
} 
Vicerrectoría de Investigación, del Centro de Evaluación Académica, todos de la UCR. También se toma en cuenta el contexto y las condiciones socioeconómicas de la época, así como el proceso de desarrollo llevado a cabo en esa etapa.

\section{Resultados}

Desarrollo académico. La UCR divide su labor académica en tres ejes sustantivos: docencia, investigación y acción social (UCR, 1974) y (UCR, 2018a). Docencia. La formación de estudiantes se brinda a través de las numerosas carreras con que cuenta la Institución, la cual se despliega a través de 13 facultades, 47 escuelas, 7 sedes y sus 5 recintos. Cuenta además con un Sistema de Estudios de Posgrado, cuya oferta académica incluye 12 doctorados, 253 maestrías y 17 especialidades, en una amplia gama de áreas del conocimiento.” (UCR, 2020b).

La Sede de Limón, ubicada en el cantón de la provincia del mismo nombre, ha requerido identificar estrategias y acciones tendientes a lograr superar los diferentes obstáculos presentados a lo largo de su existencia. Desde 2002 se realizaron sondeos anuales (UCR, 2010c) para establecer la posible oferta académica para el siguiente año, ya que los presupuestos impedían abrir todas las carreras que se solicitaban, por lo que se priorizaba las de mayor demanda (Véase figura 2).

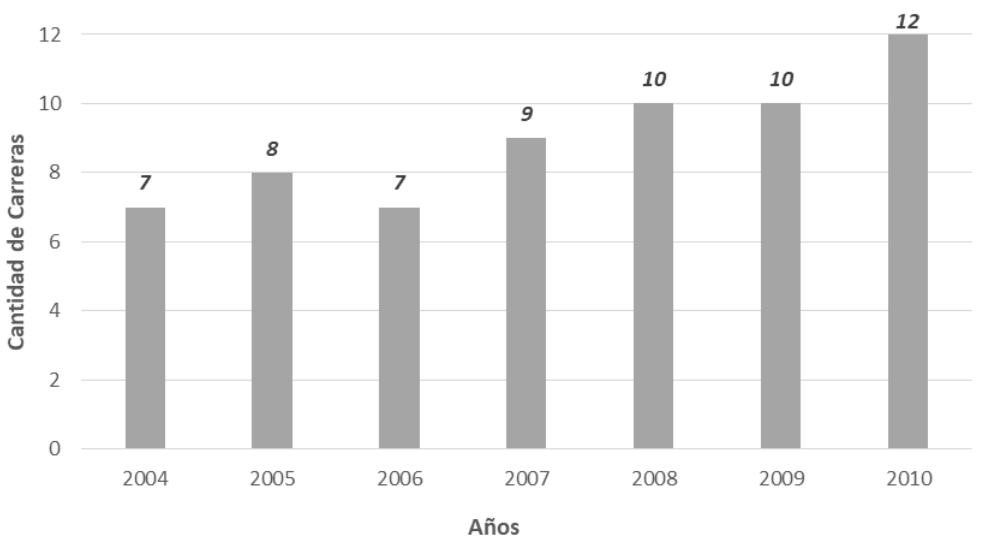

Figura 2. Cantidad de carreras ofrecidas en Sede de Limón, UCR, período 2004-2010 (Fuente: Documento Resumen Ejecutivo Informe 2004-2010, Sede de Limón, UCR).

$\mathrm{Su}$ objetivo era conocer los principales intereses de estudiantes de $10^{\circ}$ y $11^{\circ}$ de las cinco instituciones de mayor influencia en la Sede (UCR, 2010c). Como producto de los diagnósticos se seleccionaron las principales carreras para los años correspondientes a la matrícula de 2004 y 20062010. Si bien el número de estudiantes en general creció (véase figura 4), el comportamiento por carrera fue fluctuante (véase figura 3). Dichas carreras fueron las siguientes: Diplomado y Bachillerato en Administración Aduanera y Comercio Exterior, que durante los años mencionados 
aumentó su matrícula en 1400\%, al pasar de 8 estudiantes en 2004 a 120 en 2010; Bachillerato en Inglés, que entre 2004 y 2007 subió su matrícula 613\%, para luego experimentar una reducción inicial de 51,4\% entre 2007 y 2008 y, posteriormente, tener un incremento gradual. Además, se dio la apertura y fortalecimiento de nuevas promociones de Bachillerato en Informática Empresarial, que creció en un $41 \%$, y de Bachillerato en Turismo Ecológico. Estas cuatro carreras tuvieron su máxima demanda en el 2007. Sin embargo, la última mermó su matrícula, razón por la cual los coordinadores de esta carrera en las distintas sedes conformaron una comisión para estudiar el problema y reformar el plan de estudios de acuerdo con las necesidades detectadas.

Otras carreras incluyen la Licenciatura en Psicología, abierta en 2007 con 70 estudiantes, que presentó un incremento de 33,9\% en 2010; Bachillerato y Licenciatura en Contaduría Pública, que experimentó un alza de más del 333\% entre 2004 y 2010; Bachillerato y Licenciatura en Dirección de Empresas, que en el mismo lapso aumentó su matrícula en 1830\%. También se dio la apertura de Bachillerato en Educación Preescolar con Énfasis en Inglés y Bachillerato en Enseñanza del Inglés. Adicionalmente se ofrecieron las carreras de Educación para I y II ciclos con énfasis en Educación Rural, mediante convenio con la Universidad Nacional (UNA) y Licenciatura en Trabajo Social de la UCR en conjunto con la Universidad Estatal a Distancia (UNED). A nivel de posgrado, se ofrecieron la Maestría en Computación e Informática y la Maestría en Administración de Empresas. La fluctuación de matrícula que se observa en algunas carreras pudo obedecer a la apertura de nuevas opciones más atractivas para el estudiantado, lo cual generó ciertas bajas en otras. 


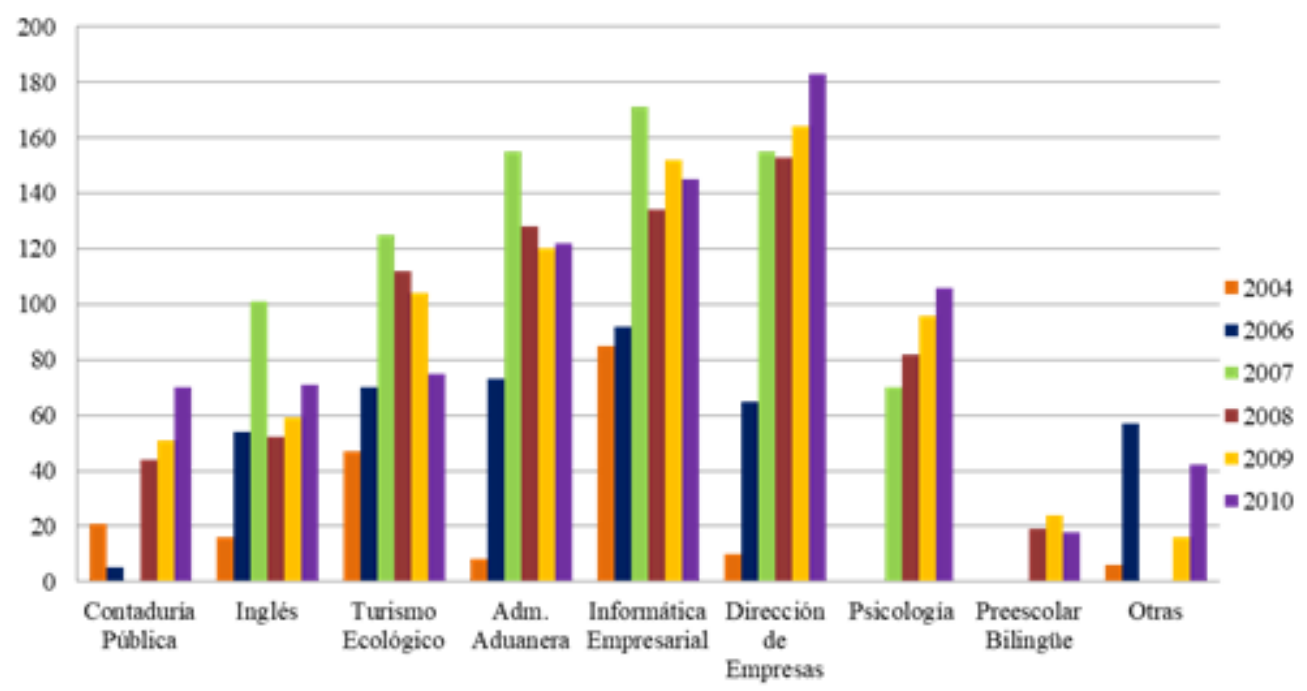

Figura 3. Cantidad de estudiantes matriculados por carrera, Sede de Limón, UCR, periodo 2004-2010 Fuente: Documento resumen Ejecutivo 2004-2010, Sede de Limón, UCR.

Esta ampliación de oferta académica, asociada a los esfuerzos de divulgación intensa y los cursos de recuperación académica para estudiantes de colegio conllevó a un aumento de la cantidad de estudiantes matriculados, la cual se incrementó de 202 en el 2002 a 789 en 2010 (figura 4), o sea, aproximadamente un 400\% (UCR, 2010b).

Por otra parte, se iniciaron gestiones para desconcentrar las carreras de Ingeniería Química e Ingeniería Eléctrica, para lo cual desde 2006 se inició la planificación presupuestaria que incluía la remodelación y equipamiento de laboratorios. Para esta última tarea, los presupuestos se fraccionaron por año, ya que la construcción y equipamiento de la Sede Interuniversitaria de Alajuela no permitió contar con presupuesto para ello oportunamente, de tal manera que cada año se compraba una parte del equipo necesario. Fue así que, posteriormente, se abrió la carrera de Ingeniería Química. 


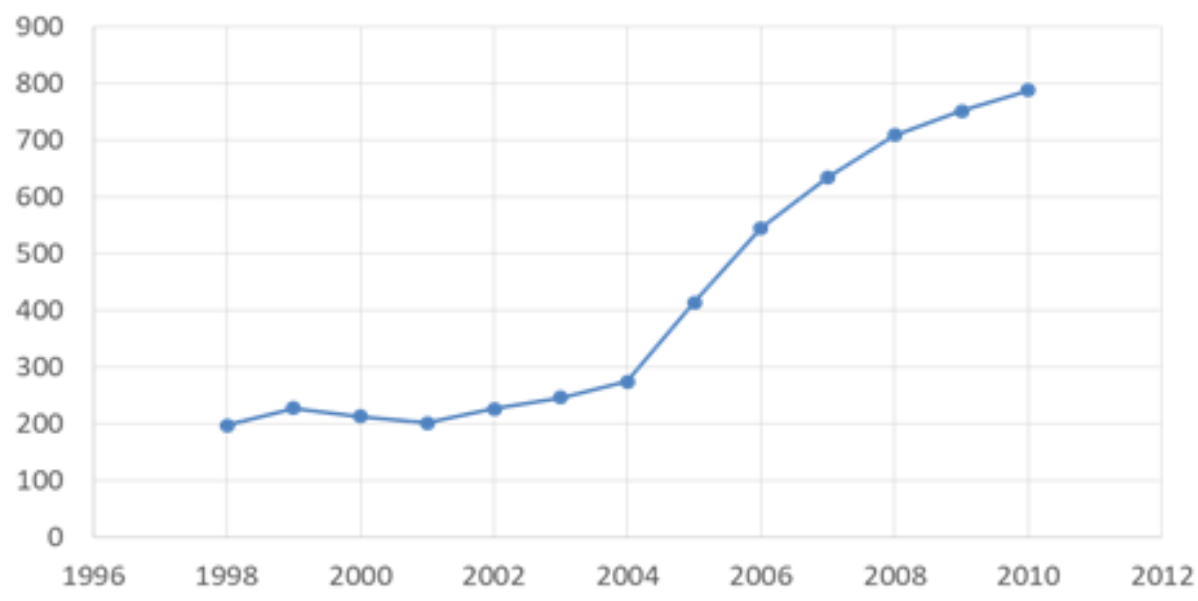

Figura 4. Cantidad de estudiantes matriculados en Sede de Limón, UCR, 1998-2010

(Fuente: Memoria 35 anos Sede de Limón, UCR)

En cuanto a graduaciones, estas ampliaron su número como resultado de un plan de acciones para incentivar y acompañar a los estudiantes que no realizaban o concluían sus trabajos finales de graduación (TFG). Es así que la graduación celebrada en IC-2010 fue de 109 graduados de grado y 2 de posgrado, para un total de 111 (UCR, 2010a), máxima graduación hasta ese momento en la historia de la Sede (véase figura 5).

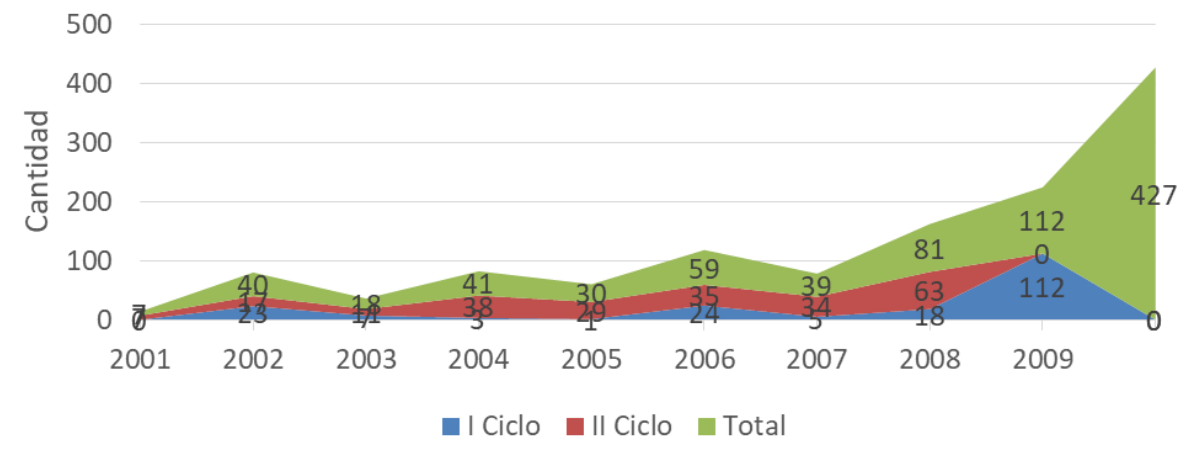

Figura 5. Cantidad de estudiantes graduados, Sede de Limón, UCR, 2002-2010 Fuente: Elaboración propia con base en Informes de Labores Dirección Sede de Limón, UCR, 2002-2010

\section{Personal docente}

Durante 2005-2010 la conformación del personal docente se incrementó de 64 docentes en 2005 a 149 en 2010 (Véase tabla 1). No obstante ello, el personal docente interino sigue representa una gran mayoría aún y, en muchas ocasiones, con contrataciones de jornada parcial y discontinua, lo cual produce inestabilidad laboral y sigue siendo un obstáculo para el desarrollo fluido de la Sede. De igual manera, los docentes con grado de Doctorado Universitario y de Maestría 
aumentaron, aunque no en el mismo porcentaje, ya que en doctorado partió de cifras muy disímiles. Por su parte, los docentes con licenciatura triplicaron su crecimiento y los que tenían título de bachillerato disminuyeron en 2010 en relación con 2005.

Tabla 1. Grado académico del personal docente según año, Sede del Caribe, UCR, 2005-2010

\begin{tabular}{|c|c|c|c|c|c|}
\hline \multirow[t]{2}{*}{ Año } & \multicolumn{4}{|c|}{ Grado Académico } & \multirow[t]{2}{*}{ Total } \\
\hline & Doctor & Máster & Licenciado & Bachiller & \\
\hline 2005 & 3 & 22 & 27 & 12 & 64 \\
\hline 2006 & 5 & 27 & 46 & 12 & 90 \\
\hline 2007 & 5 & 39 & 69 & 12 & 125 \\
\hline 2008 & 5 & 36 & 64 & 12 & 117 \\
\hline 2009 & 6 & 31 & 90 & 12 & 139 \\
\hline 2010 & 6 & 43 & 91 & 10 & 149 \\
\hline
\end{tabular}

Fuente: Documento Resumen Ejecutivo Informe 2004-2010. Sede de Limón, UCR

\section{Acción Social}

La acción social es la actividad sustantiva que permite la integración de la Universidad con la comunidad, cuya retroalimentación mediante una interacción permanente tiene como fin "poner a su servicio la capacidad académica institucional y lograr, en conjunto, las transformaciones requeridas para el mejoramiento de la calidad de vida en el país" (UCR, 2020a, parrafo primero). Se subdivide en tres áreas: Trabajo Comunal Universitario (TCU); Extensión Docente y Extensión Cultural.

La lista de proyectos de acción social de la Sede de Limón revisados en el período 20052010, arroja una relativa constancia en la cantidad de inscritos en la Vicerrectoría correspondiente, como puede apreciarse en la tabla 2. 
InterSedes, N44. Vol XXI (2020). ISSN 2215-2458

Tabla 2. Cantidad de Proyectos de Acción Social, Sede Limón, UCR, 2005-2010.

\begin{tabular}{lccc}
\hline Año & $\begin{array}{c}\text { Trabajo Comunal } \\
\text { Universitario }\end{array}$ & Extensión Docente & Extensión Cultural \\
\hline 2005 & 2 & 8 & 5 \\
2006 & 2 & 7 & 4 \\
2007 & 2 & 7 & 3 \\
2008 & 3 & 7 & 4 \\
2009 & 3 & 8 & 5 \\
2010 & 4 & 8 & 3 \\
\hline
\end{tabular}

Fuente: Elaboración propia basado en Resumen Ejecutivo Informe 2004-2010, Sede de Limón, UCR

En el período de estudio se contó con los siguientes: en TCU: 1. Informática para el desarrollo comunal; 2. Jardín etnobotánico del Caribe; 3. Organización comunitaria para la promoción de derechos de niños, niñas y adolescentes y 4. Acompañamiento de pequeñas empresas. En Extensión Cultural: 1. Rescate de valores culturales danza y teatro; 2. Calipsos limonenses; 3. Grupo artístico estudiantil Etnia; 4. Carroza universitaria; 5. Proyecto de extensión cultural general y 6. Actividades conmemorativas de la Sede. En Extensión Docente se ubican los siguientes proyectos: 1.Taller y difusión de bandas de percusión 2. Mejoramiento educativo limonense; 3. Etapa básica de música; 4.Revista radial; 5.Cursos cortos; 6.Interrelación con la persona adulta mayor; 7.Recuperación académica para estudiantes de secundaria; 8.Manejo de desechos sólidos; 9. Feria vocacional de Limón y 10. Creación de una comunidad de software libre en el Caribe.

\section{Investigación}

La UCR es la principal institución generadora de conocimiento en el país (Programa Estado de la Nación, 2020) y en Centroamérica (UCR, 2020c) y (Villegas, s/f). De esta forma contribuye de manera relevante al desarrollo del país en formación de recursos, generación y transferencia de conocimientos para la solución de problemas, la innovación y el emprendimiento. La UCR divulga el conocimiento creado a través del repositorio Kerwá (UCR, 2019b) y de 50 revistas académicas especializadas las cuales se pueden consultar en el portal de revistas institucionales (UCR, 2019c).

La cantidad de proyectos de la unidad académica reveló un comportamiento relativamente constante, con muy poca variación, como se aprecia en la tabla 3. 
InterSedes, N44. Vol XXI (2020). ISSN 2215-2458

Tabla 3. Cantidad de proyectos de investigación por año, Sede Limón, UCR 2004-2010

\begin{tabular}{cccccccc}
\hline Año & 2004 & 2005 & 2006 & 2007 & 2008 & 2009 & 2010 \\
\hline Cantidad & 8 & 6 & 7 & 9 & 10 & 11 & 9 \\
\hline
\end{tabular}

Fuente: Elaboración propia con base en el Sistema de información y gestión de proyectos, programas y actividades, SIGPRO

El tipo de investigación que se realizaba en la Sede de Limón en el período 2005-2010 (UCR, 2018b) era mayoritariamente del área de ciencias sociales (Ver tabla 4). La razón de este comportamiento tiene que ver básicamente con dos aspectos. Por una parte, el tipo de carreras que se impartía, en su mayoría de ciencias sociales y, por otra, la falta de recursos requeridos tales como equipo, materiales, infraestructura y tiempo, necesario para proyectos de ingeniería, salud, ciencias básicas y ciencias agroalimentarias.

Tabla 4. Cantidad de proyectos de Investigación por área; Sede Limón, UCR 2004-2010

\begin{tabular}{cccccccc}
\hline Área & Ingeniería & $\begin{array}{c}\text { Ciencias } \\
\text { Básicas }\end{array}$ & $\begin{array}{c}\text { Ciencias } \\
\text { Sociales }\end{array}$ & Salud & $\begin{array}{c}\text { Ciencias } \\
\text { Agroalimentarias }\end{array}$ & $\begin{array}{c}\text { Artes } \\
\text { y } \\
\text { Letras }\end{array}$ & Actividades \\
\hline Cantidad & 2 & 0 & 19 & 1 & 0 & 3 & 4 \\
\hline
\end{tabular}

Fuente: Elaboración propia con base en el sistema de información y gestión de proyectos, programas y actividades, SIGPRO

Se pueden citar los siguientes proyectos inscritos en la Vicerrectoría de Investigación, en el área de ciencias sociales: Inventario turístico de la provincia de Limón; Las comunidades religiosas de puerto Limón y su aporte al desarrollo educativo y cultural de la región; Recuperación del lenguaje de los trabajadores muelleros y su respectiva correspondencia en la cotidianidad limonense; La organización administrativa de las PYMES Turísticas del cantón central de Limón y su incidencia en la eficiencia de los servicios turísticos; Estudio de factibilidad de carreras hacia una mejor oferta Académica y laboral en Limón; Investigación de la actividad empresarial, generada alrededor de la operación portuaria y su aporte al desarrollo económico y social del cantón central de Limón; Estudio de la actividad turística para propiciar encadenamientos de las PYMES hoteleras del Caribe de Costa Rica; Diagnóstico, diseño e implementación de acciones formativas para el desarrollo de las Pymes de la Región caribeña de Costa Rica; Fortalecimiento y desarrollo de micro-emprendimientos en la provincia de Limón; Cooperación para el desarrollo local y responsabilidad ambiental y socioeconómica como 
InterSedes, N44. Vol XXI (2020). ISSN 2215-2458

elementos clave de la sostenibilidad del turismo. Cooperación entre España y Costa Rica (García, y otros, 2009); Estudio y fortalecimiento del turismo sostenible en las provincias de Guanacaste, Puntarenas y Limón; Desarrollo de la investigación intersedes; Estudio de la cooperación en las relaciones transfronterizas Costa Rica-Panamá, como motor de desarrollo Integral de Talamanca (Limón CR) y Bocas del Toro (Panamá); Construcción de un Observatorio del turismo para la región Caribe de Costa Rica (UCR, 2020d); Características de apoyo social a las personas adultas mayores en Limón CR.

En el área de ingeniería se encuentran los siguientes proyectos: Investigación aplicada en hidrodinámica naval con proyectos a la comunidad práctica nacional; Diseño de una plataforma paralela de software, para el desarrollo de aplicaciones en el campo de la educación. En el área de artes y letras: El currículo de inglés y su práctica en escuelas públicas del casco urbano del cantón central de Limón; Estudio etnomusicológico del calipso limonense; Estudio, diagnóstico y evaluación de la enseñanza del inglés oral en los colegios bilingües y universidades de Limón. Además un proyecto que puede considerarse tanto del área de la salud como de las ciencias sociales: Síndrome de agotamiento en el trabajo y estrategia de afrontamiento en docentes de secundaria en dos comunidades del cantón central de Limón.

Actividades de promoción de la investigación como: Ciclo de conferencias, cursos y seminarios; II seminario: Estado de la investigación en el Caribe de C.R.; Seminario de acción social e investigaciones del Caribe Limón 2010. Además, se realizaron seminarios internacionales con académicos prestigiosos de universidades extranjeras, todo lo cual propició un aumento de la proyección e impacto de la universidad en la comunidad. Es necesario recalcar que estos proyectos en su mayoría, se desarrollaron sin carga (jornada) académica asignada a sus investigadores.

\section{Desarrollo estudiantil}

La caracterización de la población estudiantil, según el género, muestra un aumento del porcentaje del estudiantado femenino de $47 \%$ en 2004 a 58\% en 2010, pero el grupo masculino de estudiantes disminuyó en ese período, según muestra la figura 6. 


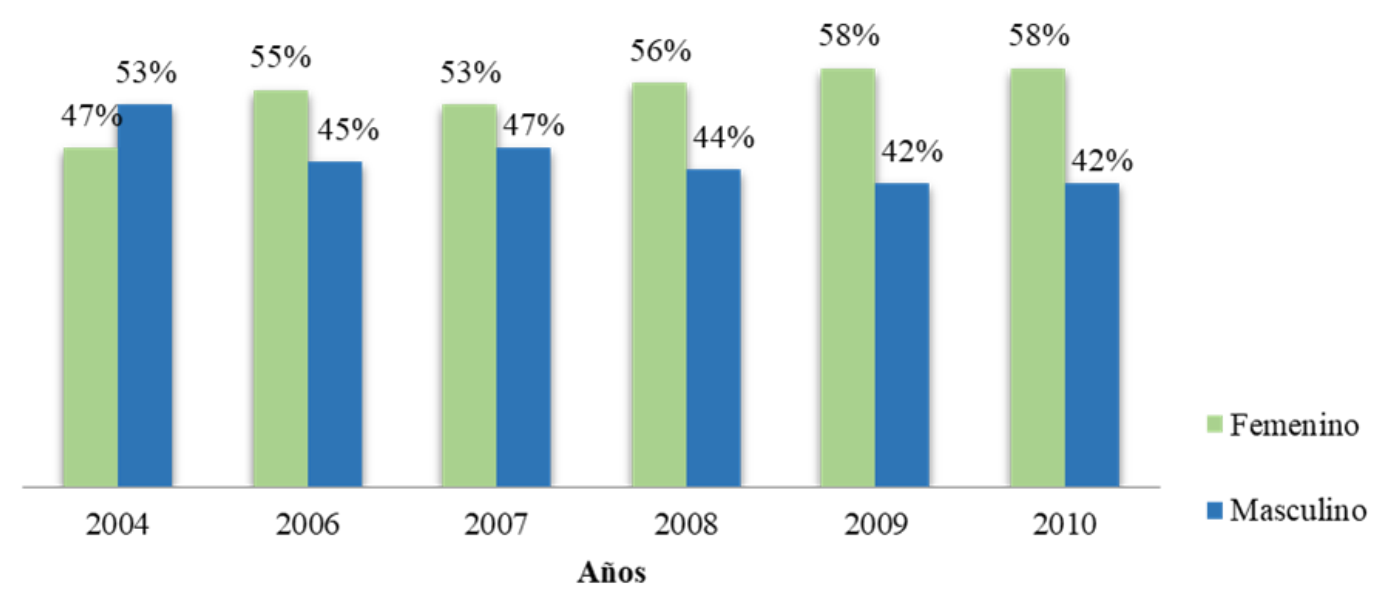

Figura 6. Estudiantes distribuidos por género, Sede de Limón,2004-2010 Fuente: Elaboración propia con base en Informes anuales de la Coordinación de Vida Estudiantil, Sede de limón, UCR. 2004-2010

En el período revisado, a diferencia de los inicios de la Sede, la población estudiantil ha estado conformada en su mayoría por jóvenes, cuyas edades no superan los 25 años. Este grupo etario constituía un 78\% en 2004, y en el período 2006-2010 varió entre un 88\% y 91\%. (Véase figura 7).

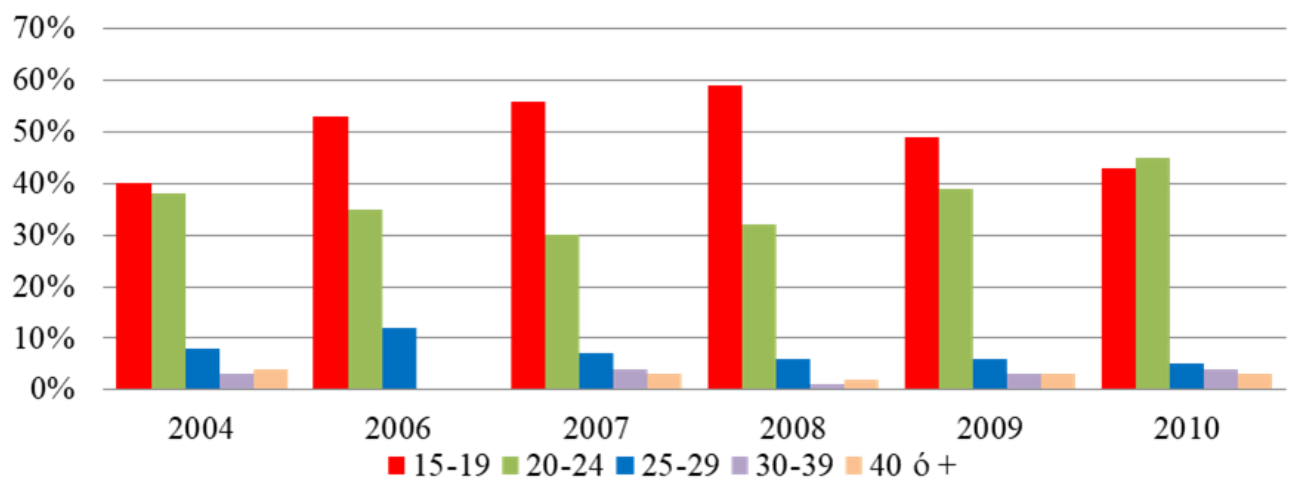

Figura 7. Edad de los Estudiantes Sede de Limón, UCR, 2004-2010 (Elaboración propia con base en Informes anuales de Coordinación de Vida Estudiantil, Sede de Limón, UCR, 2004-2010)

Otro aspecto importante que permite identificar la situación socioeconómica de los estudiantes gira en torno a las becas que la Universidad asigna. En ese período, esa distribución se hacía en doce categorías que iban de la cero (sin beneficios) hasta la $11^{17}$ (UCR, 1987) con ayuda

\footnotetext{
${ }^{17}$ A partir del año 2013 las categorías de becas socioeconómicas se modificaron a cinco tipos (1-5). La categoría 5 equivale a: Exoneración del 100\% del costo de matrícula y 100\% en costos de laboratorios, actividad deportiva,
} 
económica, alimentación, reubicación geográfica, residencia, transporte y libros. En 2004, un 83\% contaba con algún tipo de beca, mientras que en 2010 el porcentaje cubría casi a la totalidad de los estudiantes $(99,84 \%)$. La tendencia del período, apuntaba a que las becas 11 se incrementaban (UCR, 2010d) año con año (Véase figura 8), situación muy importante en una región con altos niveles de pobreza y de estudiantes provenientes de zonas rurales, a los cuales, sin esta ayuda les sería imposible acceder a la educación superior. Esta alza notable en 2010 se debe básicamente al incremento de matrícula de estudiantes en general.

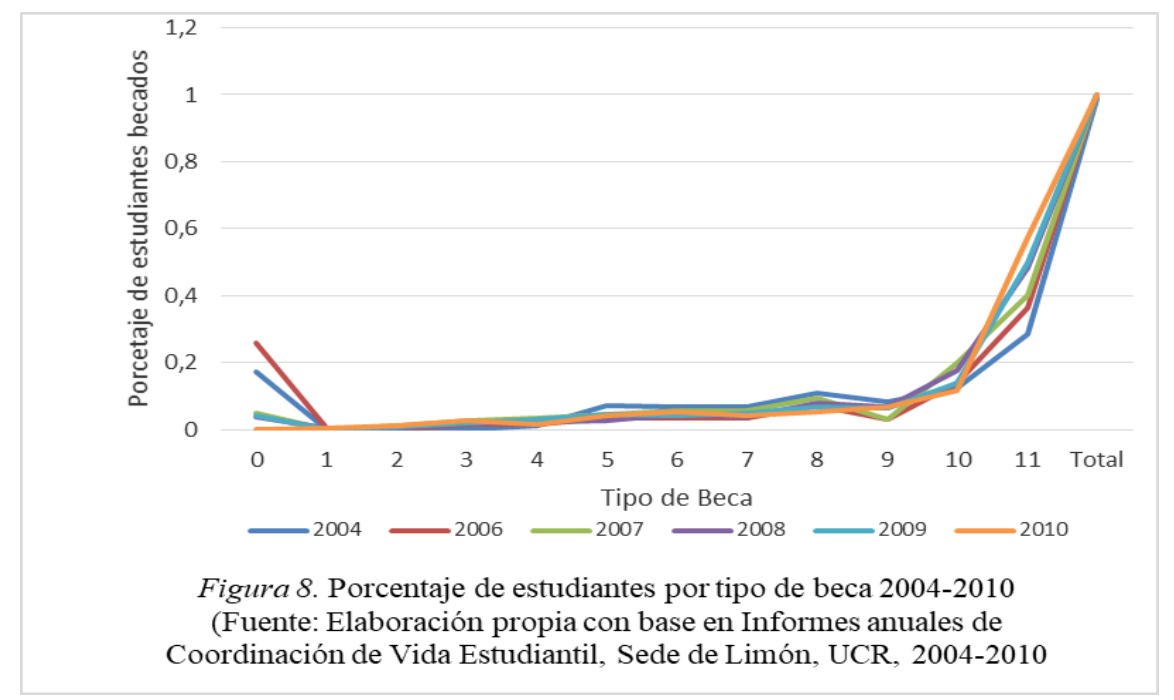

\section{Gestión administrativa}

Las oficinas administrativas están orientadas al servicio de las labores sustantivas de la Universidad y vinculadas con los principios, propósitos y funciones definidos en el Estatuto Orgánico (UCR, 1974). Cada abril-mayo, todas las unidades académicas de la UCR deben formular el plan-presupuesto del siguiente año. Esta fase del proceso de planificación para la elaboración del Plan Anual Operativo (PAO) ${ }^{18}$ y su presupuesto, es la base para la asignación y obtención de los recursos necesarios para atender adecuadamente los requerimientos del Plan de Desarrollo Institucional y en particular también de las sedes.

graduación y reconocimiento de estudios. Un monto económico para gastos de carrera o carreras. Cuando corresponde, se otorga un monto por pobreza extrema. Un 100\% para gastos de transporte o alojamiento (reubicación geográfica o residencias estudiantiles); $100 \%$ del costo del almuerzo y otros tiempos de comida y un 100\% en servicios básicos de optometría y odontología. Además, préstamo de libros y de dinero para la adquisición de libros, equipo, instrumentos u otros. Esta reforma entró en vigencia a partir del I ciclo lectivo 2015 (UCR, 2015).

18 "Documento que se entrega a la Contraloría General de la República en el que resume las principales actividades institucionales, por programa, a realizar en un año. Los objetivos propuestos se vinculan con las políticas y el plan de desarrollo institucional, y se evalúa dos veces por año" (UCR, 2019d). 
En el período de estudio se aumentó el presupuesto operativo, cuyo incremento fue mayor al 500\% entre 2004 y 2010 pasando de 321 millones a 1500 millones de colones en total para las cinco unidades ${ }^{19}$ (Véase figura 9) (UCR, 2010c).

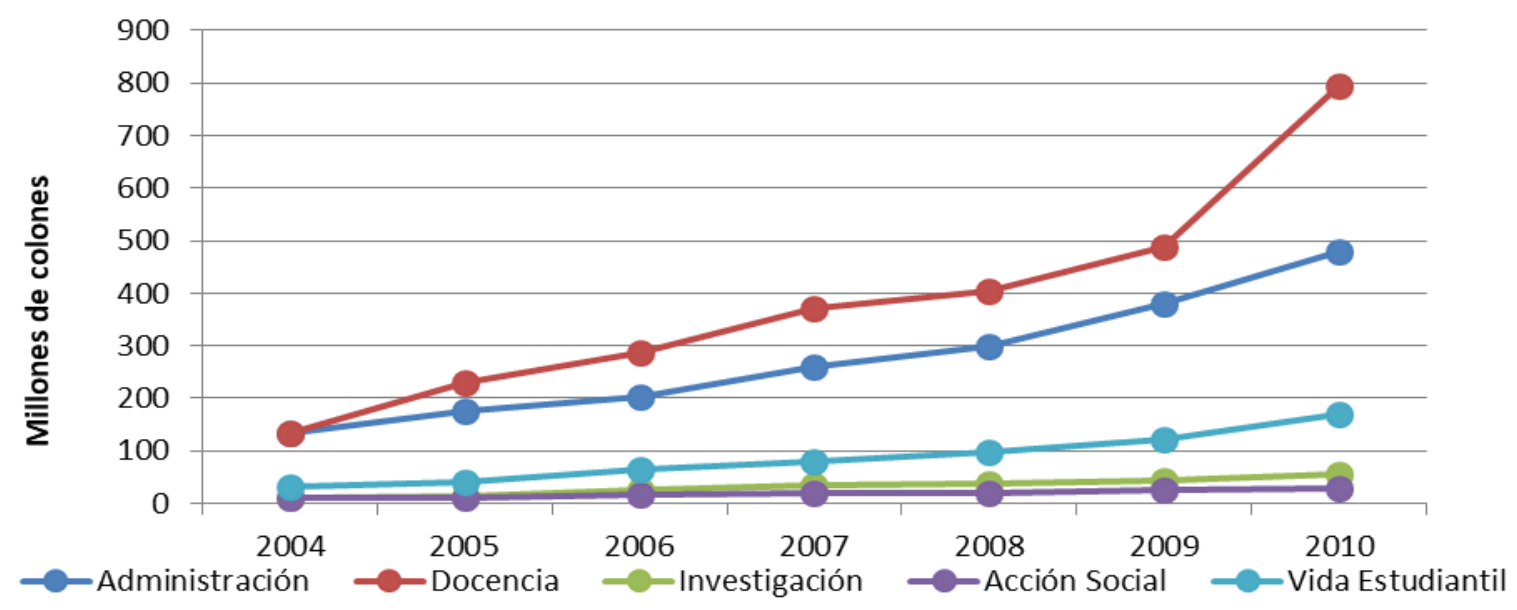

Figura 9. Plan-presupuesto anual operativo, Sede de Limón UCR

(Fuente: Doc. Resumen ejecutivo Informe Sede de Limón, UCR, 2004-2010)

En cuanto a jornadas académicas se debe señalar la consecución de mayor cantidad de presupuesto docente, el cual pasó de $18,5 \mathrm{TC}^{20}$ propios (2002) a 45,5 TC propios $^{21}(2010)$, los cuales sumados al presupuesto de apoyo $^{22}$ de la Vicerrectoría de Docencia y la Rectoría, 12 TC, totalizaban 57,5 TC. (Véase figura 10).

\footnotetext{
${ }^{19}$ Administración, Docencia, Investigación, Acción social y Vida Estudiantil.

${ }^{20}$ Un TC: tiempo completo equivale a 40 horas laborales por semana.

${ }^{21}$ Tiempos completos propios: presupuesto en jornadas laborales destinadas a docentes que pertenecen a la Unidad Académica de manera permanente y con plena potestad de uso.

${ }^{22}$ Presupuesto de apoyo: presupuesto en jornadas laborales destinadas a docentes concedidas temporalmente a la Unidad Académica, ya sea de parte de la Vicerrectoría de Docencia o la Rectoría u otra Vicerrectoría.
} 


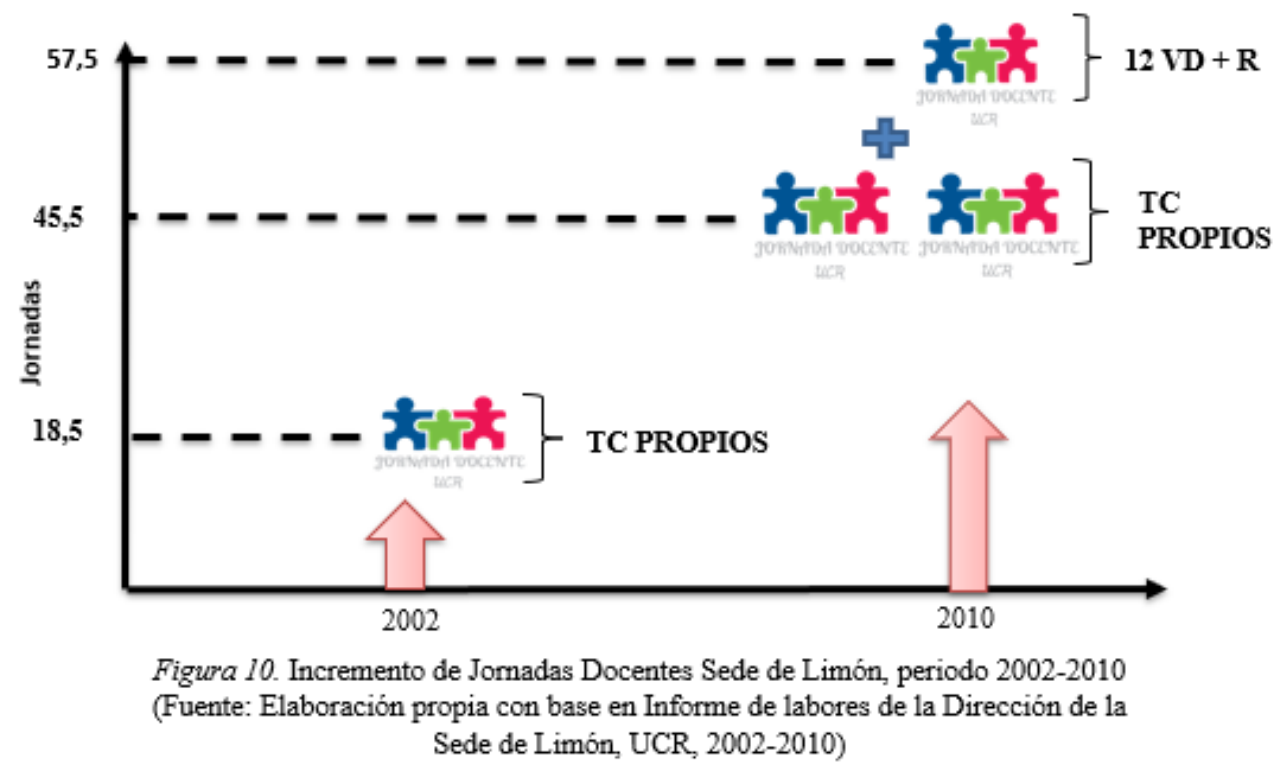

En materia de infraestructura (UCR, 2010b) se construyó un nuevo edificio para la Biblioteca, un aula multiuso; un moderno edificio para residencias estudiantiles ${ }^{23}$ totalmente equipadas con un área de 1300 metros cuadrados de construcción, con capacidad para albergar 65 estudiantes en 21 habitaciones. El pabellón 1 se remodeló para uso de la Etapa Básica de Música, con cubículos para docentes, bodega de activos y los consultorios médico y odontológico. Además, se rediseño el pabellón 2, con el objetivo de instalar los laboratorios de química, física y cómputo con sus requerimientos; además de un laboratorio de idiomas. Se efectuaron importantes reparaciones al gimnasio, donde además se acondicionó una bodega para suministros y una sala de entretenimiento para estudiantes. Por otra parte, se realizó la ampliación, remodelación y reequipamiento de la soda y una serie de obras menores. Así mismo, se logró la pavimentación de acceso a la Sede y las calles internas, así como espacios para estacionamiento y aceras, con su respectiva iluminación. En cuanto a equipamiento, se modernizó la central telefónica y se instalaron: un sistema de fibra óptica, internet, red inalámbrica, estaciones de trabajo y aire acondicionado, nuevas computadoras y audiovisuales en toda la Sede. Por otra parte, se amplió la flotilla de vehículos. (UCR, 2010b).

Con el apoyo de la Oficina Ejecutora del Plan de Inversiones (OEPI) se diseñó un plan maestro (UCR, 2010b) para la Sede. En este se planificaba, entre otros proyectos de infraestructura,

\footnotetext{
${ }^{23}$ La Sede de Limón abrió su primera residencia en 1988, con la modalidad de casa de alquiler para diez estudiantes varones; en 1993 abrió otra residencia de la misma modalidad para alojar 8 estudiantes mujeres. En el 2010, esta sede inauguró un Edificio de Residencias Estudiantiles con una capacidad para 65 estudiantes (UCR, 2010a).
} 
un edificio de las artes, un anfiteatro, un auditorio, un nuevo comedor estudiantil, un módulo de profesores, una bodega de activos, estacionamientos bajo techo, un módulo de salud, un módulo adicional de aulas, una casa de huéspedes, nuevos vestidores para la piscina y un nuevo edificio administrativo. Este plan no alcanzó a ejecutarse en el período de estudio. Paralelamente fue planteado el diseño y presupuesto del nuevo acceso para la Sede.

\section{Conclusiones}

El tema regionalización, históricamente, ha sido objeto de análisis en variados ámbitos de muchos países del mundo, especialmente en América Latina. Mattos (1990); O'Brien (1999); Abarca (2010); Montecinos (2013); Martínez (2002); Rama (2015); Baltodano (2015) y otros autores coinciden en que el tópico trae implícita la relación centro-periferia con un poder dominante de la región central, percepción que en la práctica se ha vivenciado en el caso de la regionalización de la educación superior costarricense. Quienes impulsaron el inicio de la regionalización de la educación superior, como Carlos Monge (Castro, 2009), poseían las mejores intenciones de su expansión a las regiones. Sin embargo, su desarrollo se ha visto obstaculizado por diferentes aspectos que la han frenado en su avance, tanto en forma como en contenido, que responda a las reales necesidades de las comunidades regionales para propiciar un desarrollo en ellas. Aunado a lo anterior, como se ha expuesto en este documento, entre las diferentes sedes regionales universitarias, ha habido importantes diferencias en su evolución. Producto de esto, en la UCR, por ejemplo, una de las sedes más rezagadas, precisamente ha sido la Sede de Limón (CONARE, 2013). La Sede de Limón, representa un ejemplo de creación y desarrollo vinculado a múltiples complicaciones y esfuerzos, sustentado inicialmente por las demandas y consecuente apoyo de la comunidad (UCR, 1995). Los índices presentados en PEN (2005); en los Estados de la Educación (IV, V y VI) y en INEC (2019), entre otros, exponen como los factores: pobreza, desempleo, calidad de la educación primaria y secundaria en las zonas rurales de la provincia de Limón, con reducida infraestructura y limitado personal docente, han incidido en las posibilidades históricas para que la población de la región acceda a la educación superior

Por otra parte, las limitaciones presupuestarias que afectan en mayor medida a las sedes regionales, impide la creación de carreras en forma oportuna, así como la apertura de aquellas a las que aspiran el estudiantado y las empresas. De este modo, las escuelas de la Sede Rodrigo Facio establecen reglas para su apertura en otras regiones, cuya implicación significa tiempo en esfuerzos adicionales para la consecución de recursos, los cuales siempre son insuficientes para realizar 
estudios de factibilidad, la logística, el equipamiento, la infraestructura y la contratación de la cantidad de personal académico necesario.

Este panorama ha representado un reto para quienes laboran en la Sede del Caribe y para quienes lo han liderado. Por esta razón, el somero análisis que se ha pretendido exponer en este escrito, constituye una pequeña parte de su quehacer en más de cuarenta años de existencia. Los resultados obtenidos en el desarrollo de la Sede de Limón, muestran una oferta académica mayor, lo cual parecía muy complicado a inicios del período de estudio, año 2002. En consecuencia, se produjo un aumento en la cantidad de esta. Las carreras ofertadas resultaron pertinentes en su momento, obtuvieron demanda y cumplieron su rol en la zona. Creció la matrícula y se dispuso de mayor cantidad tanto de personal docente como administrativo y en general de recursos de todo tipo, lo cual podría parecer óptimo; a pesar de ello, es necesario recordar que se partió de una posición de sustancial desventaja en comparación con otras sedes regionales. Es así, que aunque, los logros del período de estudio y los conseguidos en períodos posteriores en la Sede han sido significativos, aún se está lejos de satisfacer las necesidades de esta región, la cual, tal como lo publican medios de comunicación (Cordero, 2019), enfrenta actualmente un aumento acelerado del desempleo y de las condiciones de vida de su población (INEC, 2019).

La situación posterior a la etapa de estudio (CONARE, 2019) ha demostrado que los problemas medulares que sufre la educación terciaria no han cambiado trascendentalmente, continúa la desigualdad entre la oferta académica de las regiones y del valle central, así como las potenciales oportunidades de la población de la región Caribe para acceder a la educación superior. En los últimos diez años ha habido importantes estudios como los del Estado de la Educación, que demuestran que hay que realizar cambios y mejoras que permitan una regionalización integral para propiciar de manera armónica el desarrollo de la región Caribe (CONARE, 2015, 2017, 2019). También en estos años ha habido esfuerzos de articulación interuniversitaria pública con el fin de invertir de manera eficiente y eficaz el presupuesto asignado para apoyar la regionalización de la educación superior estatal. Con todo, el tema sigue pendiente, ya que el objetivo es alcanzar una oferta de educación inclusiva, articulada, pertinente, equitativa y diversa en la región. Esencial es que haya un plan articulado e integral de regionalización de la educación superior y una mejora sustancial de la enseñanza secundaria y superior sustentado en un financiamiento adecuado y estable. Por lo tanto es de vital importancia para la región estimular más reflexiones sobre este 
tema, e impulsar propuestas para mejorar la situación planteada, pues queda al descubierto el desarrollo generado a partir del año 2010. Con base en un análisis adicional de la cuestión, desde esa fecha al presente, se podrían plantear y enfocar políticas que coadyuven a crecer y seguir ofreciendo educación comprometida en la región.

\section{Agradecimientos}

Un agradecimiento especial por sus aportes a la Máster Saray Córdoba y a la Máster Jeannette Soto, quienes han revisado el manuscrito y realizado observaciones pertinentes para mejorarlo, además por la traducción que esta última muy gentilmente realizó. También a la Bachiller Rebeca Sánchez y al estudiante Andrey Muñoz, asistentes en la Sede del Caribe, por su colaboración en mejora de gráficos.

\section{Referencias}

Abarca, O. (2010). La región como concepto y como problema en las investigaciones históricas. En O. Abarca, J. Bartels, \& J. J. Marín, De Puerto a región. El Pacífico Central y sur de Costa Rica 1821-2007 (págs. 23-41). San José, Costa Rica: Alma Mater. Obtenido de https://www.jstor.org/stable/2649567

Anónimo. (7 de agosto de 1996a). Limón exige intervención de JAPDEVA en Estiba. La Nación. Obtenido de https://www.nacion.com/archivo/limon-exige-intervencion-de-japdeva-enestiba/Z7FGPLCY55D4RFUAWPI2VAKF2M/story/

Anónimo. (2 de septiembre de 1996b). Fuerte baja en costo de la estiba. La Nación. Obtenido de https://www.nacion.com/archivo/fuerte-baja-en-costo-de-laestiba/LVE4RPNQYNBWFK5LJWD4BHC6FM/story/

Arguedas, A. C. (25 de agosto de 2004). Proyecto de ley Creación de un fideicomiso para el pago de una indemnización y finiquito a los trabajadores de la estiba y desestiba de los muelles de Limón y Moín. Obtenido de Opinión jurídica: 104-J:

http://www.pgrweb.go.cr/scij/Busqueda/Normativa/Pronunciamiento/pro_detalle.aspx?pa ram1=PRR\&param6=1\&nDictamen=12750\&strTipM=R

Arias, L. (05 de junio de 2018). La frustrada regionalización universitaria. Semanario Universidad. Obtenido de https://semanariouniversidad.com/opinion/la-frustradaregionalizacion-universitaria/

Baltodano, J. (2015). Obtenido de El Modelo de Regionalización de la Universidad de Costa Rica y el Principio de Igualdad Constitucional: Implicaciones Fáctico-Jurídicas . Tesis para 
optar por el grado de Licenciatura en Derecho.:

http://repositorio.sibdi.ucr.ac.cr:8080/jspui/handle/123456789/3057

Castro Sánchez, S. (2011). Costa Rica frente a la regionalización de la educación superior. El primer centro universitario regional en San Ramón, Alajuela. InterSedes, 10(18), 174204. Obtenido de https://revistas.ucr.ac.cr/index.php/intersedes/article/view/1033/1094

CONARE. (2005a). Primer Informe Estado de la Educación Costarricense. Programa Estado de la Nación en Desarrollo Humano Sostenible de la Educación, San José, Costa Rica. Obtenido de https://estadonacion.or.cr/informes/?current=3

CONARE. (2005b). Plan Nacional de la Educación Superior Universitaria Estatal 2006-2010. (O. d. Superior, Ed.) San José, Costa Rica: CONARE.

CONARE. (2008). II Estado de la Educación. CONARE. San José, Costa Rica: Programa Estado de la Nación . Obtenido de Capítulo 3: http://repositorio.conare.ac.cr/bitstream/handle/20.500.12337/1145/Panorama\%20General $\% 20 \mathrm{de} \% 201 \mathrm{a} \% 20$ Formaci\%c3\%b3n\%20Docente_Cap\%c3\%adtulo\%203_II\%20Informe. pdf? sequence $=1 \&$ isAllowed $=y$

CONARE. (2013). IV Informe del Estado de la Educación. CONARE. San José, Costa Rica: Programa Estado de La Nación. Obtenido de https://estadonacion.or.cr/informes/?current=3

CONARE. (2015). V Informe del Estado de la Educación Costarricense. CONARE. San José, Costa Rica: Programa Estado de la Nación. Obtenido de https://issuu.com/estadonacion/docs/estado-educacion-5-2015

CONARE. (2017). VI Informe de Educación. San José, Costa Rica: Programa Estado de la Nación. Obtenido de https://www.estadonacion.or.cr/educacion2017/assets/ee6-informecompleto.pdf

CONARE. (2019). VII Informe del Estado de la Educación Costarricense. San José, Costa Rica: Programa Estado de la Nación. Obtenido de https://www.uned.ac.cr/viplan/images/cppi/documentos/ESTADO-EDUCACION-2019WEB.pdf

Consejo Nacional de Educación Superior (CESU). (2014). Acuerdo por lo Superior 2034. Propuesta de política pública para la excelencia de la educación superior en Colombia en el escenario de la paz. Bogotá, Colombia. Obtenido de Propuesta de Lineamientos de Política Pública sobre Regionalización de la Educación Superior en 2034. Documento de análisis preliminar en 2034.: https://www.dialogoeducacionsuperior.edu.co/1750/articles321515_recurso_1.pdf 
Cordero, M. \&. (02 de abril de 2019). Limón: Una olla de presión al límite. Semanario Universidad. Obtenido de https://semanariouniversidad.com/pais/limon-una-olla-depresion-al-limite/

García Muñoz, H. y. (julio-diciembre de 1998). Educación y desigualdad social. Revista Mexicana de Investigación Educativa, 3(6), 317-345. Obtenido de https://www.redalyc.org/articulo.oa?id=140/14000607

García, P., Lepe, I., Albertos, M., Anderson, W., Gil, M. D., \& Martínez, G. (2009). Cooperación España-Costa Rica para el Desarrollo Local. Presponsabilidad Ambiental y socioeconómica como elementos clave de la sostenibilidad del Turismo. Murcia; España: UCAM Publicaciones.

Instituto Nacional de Estadísticas y Censo (INEC). (2019). Encuesta Nacional de Hogares julio 2019. San José, Costa Rica. Obtenido de https://www.inec.cr/sites/default/files/documetos-biblioteca-virtual/reenaho2019.pdf

Mattos, C. (1990). La descentralización, ¿una nueva panacea para impulsar el desarrollo local? Cuadernos de Economía(14), 173-194. Obtenido de https://revistas.unal.edu.co/index.php/ceconomia/article/view/19268/20214

Ministerio de Planificación de Costa Rica (MIDEPLAN). (febrero de 2020). MIDEPLAN. Obtenido de https://www.mideplan.go.cr/que-es-mideplan

Montecinos, E. (2013). De la descentralización administrativa a la descentralización política. Propuestas de reformas y políticas públicas para un Chile descentralizado, democrático y participativo. Documento de Trabajo $N^{\circ} 10$. Serie Estudios Territoriales. (www.gual.ufsc.br, Ed.) Santiago, Chile. Obtenido de Documento de Trabajo No 10 : http://www.rimisp.org/wpcontent/files_mf/1371758341DOCUMENTODETRABAJO10_MONTECINOS.pdf

O'Brien, M. (octubre de 1999). On Observing de Quicksand. The American Historical Review, 104(4), 1202-1207. Obtenido de https://www.jstor.org/stable/2649567?seq

Programa Estado de la Nación (PEN). (2005). XI Informe del Estado de la Nación en Desarrollo Humano Sostenible. San José, Costa Rica: Programa Estado de la Nación. CONARE.

Programa Estado de la Nación. (2020). Principales instituciones de conocimiento científico ubicadas en Costa Rica 2000-2018. Obtenido de Estado de las Capacidades en Ciencia, Tecnología e innovación (ECCTI). Hipatia: https://hipatia.cr/dashboard/publicacionescientificas 
Rama, C. (mayo de 2015). Nuevas formas de regionalización de la educación superior en América Latina: Las universidades, red y los cluster universitarios. Revista Gual, 8(2), 302-328. Obtenido de www.gual.ufs.br

Ruiz, Á. (2001). Las Universidades Privadas. En Á. Ruiz, La Educación Superior en Costa Rica. Tendencias y retos en un nuevo escenario histórico (Primera ed., págs. 39-64). San José: Editorial de la Universidad de Costa Rica.

Soto-Quirós, R. (21 de abril de 2012). Etudes Caribeennes. Obtenido de Desarrollo, etnia y marginalización : imágenes del puerto caribeño de Limón Costa Rica (1838-1967): https://journals.openedition.org/etudescaribeennes/5715?lang=es

UCR. (1974). Estatuto Orgánico de la Universidad de Costa Rica. Obtenido de Consejo Universitario: http://www.cu.ucr.ac.cr/normativ/estatuto_organico.pdf

UCR. (1987). Reglamento de adjudicación de becas y otros beneficios a los estudiantes. Obtenido de Consejo Universitario: http://cu.ucr.ac.cr/normativ/adjudicacion_de_becas.pdf

UCR. (1995). XX Aniversario de la Educación Superior en Limón. Memoria. San José, Costa Rica: Oficina de Divulgación de la Universidad de Costa Rica (ODI).

UCR. (2003). Aspectos Fundamentales de las Actividades de las Sedes Regionales. Período 1993-2003. San José: Inédito.

UCR. (2004). Proceso de Admisión e Ingreso a Carrera en la UCR. Propuesta Sedes Regionales. San José: Inédito.

UCR. (2010a). 35 Años Sede de Limón (Memoria). San José, Costa Rica: Oficina de Divulgaciòn e Informaciòn (ODI).

UCR. (2010b). Informe de labores de la Dirección de la Sede de Limón, UCR, 2002-2010. Limón, Costa Rica: Inedito.

UCR. (2010c). Resumen Ejecutivo Informe 2004-2010. Sede de Limón, UCR. Limón, Costa Rica: Documento inedito.

UCR. (2010d). Informe Coordinación de Vida Estudiantil. Caracterización de la población estudiantil Sede de Limón, 2004-2010. Limón, Costa Rica: Inédito.

UCR. (2015). Consejo Universitario (CU). Obtenido de Reglamento de Adjudicación de Becas a la población estudiantil: http://www.cu.ucr.ac.cr/normativ/adjudicacion_de_becas_2015.pdf 
UCR. (2018a). Ampliación Plan Estratégico Institucional 2018-2020. (Rectoría, Ed.) San José, Costa Rica. Obtenido de https://www.ucr.ac.cr/medios/documentos/2018/transparencia_pei_2018-2020.pdf

UCR. (2018b). SIGPRO. Sistema de Información y Gestión de proyectos, programas y Actividades. Obtenido de https://vinv.ucr.ac.cr/sigpro/web/projects/page/1 ?keyword=SEDE + del + Caribe \&state $=0$

UCR. (2019a). Oficina de Recursos Humanos. Vicerrectoría de Administración. Obtenido de http://orh.ucr.ac.cr/manual-puestos/glosario

UCR. (2019b). Repositorio Kérwá. Obtenido de Repositorio Institucional de la Universidad de Costa Rica.: www.kerwa.ucr.ac.cr

UCR. (2019c). Portal de revistas académicas. Obtenido de Universidad de Costa Rica: https://revistas.ucr.ac.cr

UCR. (2019d). Oficina de Planificación Universitaria (OPLAU). Obtenido de Plan Anual Operativo: http://oplau.ucr.ac.cr/es/publicaciones/plan-anual-operativo

UCR. (2020a). Acción Social en la UCR. Obtenido de 80 Aniversario Universidad de Costa Rica: https://www.ucr.ac.cr/accion-social/

UCR. (2020b). Docencia en la UCR. Obtenido de Universidad de Costa Rica: https://www.ucr.ac.cr/docencia/

UCR. (2020c). Investigación en la UCR. Obtenido de Universidad de Costa Rica: https://www.ucr.ac.cr/investigacion/

UCR. (2020d). Observatorio de Turismo sostenible del Caribe de Costa Rica (OBTURCARIBE). Obtenido de OBTURCARIBE: www.obturcaribe.ucr.ac.cr

UCR. (2020e). Oficina de Registro. Estadística de admisión población estudiantil por etapas del proceso, procedentes de la provincia de Limón, período 2010-2011. febrero 2020. (O. d. Sistema de Información Universitaria (SIUCR), Recopilador) San José, Costa Rica.

Villegas, M. (s/f). Publicaciones científicas indexadas en Centroamérica enero 2000-junio 2008. Obtenido de UCR, PROINNOVA: http://www.kerwa.ucr.ac.cr/bitstream/handle/10669/319/Publicaciones\%20cient\%c3\%adf icas\%20indexadas\%20en\%20Centroam\%c3\%a9rica.pdf?sequence $=1 \&$ is Allowed=y 